\title{
Public food policies: epistemological and systemic restructuring
}

\begin{abstract}
Summary
The redefinition of public policies food should clarify the corresponding analytical approaches to a broader, concerning the meeting the food needs of individuals, being feasible towards the social and natural intone of these; generating a paradigmatic release of the current system.Implicit this parameter, the epistemological knowledge in one, not oppressive, liberator sense contributes to the decolonization of ideologies rooted consumerist, conducive to the deterioration of these environments' wellness food and carecientes systems axes of food law, concerning a universal right. Thus, the sense of diversification of food public policies must recreate the evolving needs of welfare in a systemic process of promotion, prevention, correction and creating food Entonox epistemological rather than oppressive colonization.
\end{abstract}

Volume 7 Issue 2 - 2020

\author{
Salatiel Ávila Serrato \\ Department of Nursing and Obstetrics, University of \\ Guanajuato, Mexico
}

Correspondence: SalatielÁvila Serrato, Department of Nursing and Obstetrics, University of Guanajuato, Mexico, Tel 417 10780 29, Email salatiel.avila@ugto.mx

Received: March 10, 2020 | Published: April 23, 2020

\section{Object of the article}

Faced with the great challenges of the agricultural sector in Mexico regarding food production and in the face of growing social demand, the need to implement complementary production models seeking to satisfy the social demands of products with high nutritional quality is emphasized, with production processes being used related to the care of the socio-environmental environment. In this context, agroecology and alternative forms of agriculture have gained interest in representing concrete ways disseminating these challenges. On the other hand, the inclusion of globalizing foods in the different socioenvironmental environments has led to structural changes in the dietary intake of populations, contributing to the adaptation of high consumption of foods with high energy density. In this sense, the implementation of production languages and the promotion of local food availability allows for food diversification, with the objective of reducing the acquisition of food with high energy density, thus preventing chronic-degenerative diseases resulting from dietary factors adopted by structures. social that make up the different socioenvironmental environments. In such a way, that this corresponds to the primordial need to establish the political-social actions of the first order agenda in the axis of food sovereignty, based on healthy and sustainable diets that correspond to an environment with the primary needs of a food system.

\section{Introduction}

\section{Decolonization of the environment: vision of ideological change}

In Mexico, the epidemiological increase in situations of double burden of malnutrition has been determined by different specific factors in the consequent chronic degenerative diseases in the population. Particularly malnutrition, overweight and obesity have increased figures due to the nutritional cultural transition, accentuating the consumption of foods with high energy density, which has presented the spread of the traditional diet, achieving with it the permeability of a consumer purchasing system in the different populations, forming unhealthy nutritional habits, which, favoring the commercial demand for unhealthy foods. Likewise,Notably, the current state of public food policies does not contribute to satisfying the needs of the entire population towards the availability and access of all food, that is, the sufficiency of existing food for the entire population and the correct acquisition of these in each of the homes. Without losing sight of the fact that the State has the obligation and the duty of a systemic implementation of public policies, which guarantees a healthy, adequate and quality diet in micronutrients, micronutrients and calories, referring to the sociocultural diversification of the entire population that constitutes the state and, which manifests the scope of the well-being of all families.

Thus, the development of each and every one of the food programs will restructure the paradigmatic questions that intervene in the mechanisms implicit in these public policies. Giving the word decolonize is based on the new discourse of a global and current policy, which does not start from a single interculturality, rather, to multicultural expression. It should be noted that decolonizing not only represents today and now; it starts from a colonial anthropology, as represented by Alison Spedding P, on the reconstitution of historical, economic movements, etc. in a neoliberal policy. So behold, the following question is generated, why the food must be decolonized? This question is given under the paradigm of a criterion for adoption by societies in a new era of cultural adaptation, which not only involves a context of sociability. It goes further, from the meaning of itinerant neoliberalist policies, which contribute to a new linear ideology of privatizing mechanisms. This privatization will characterize the decline of food production to an entire society, whose resources will be limited in the face of the vulnerability that is and will be caused; in addition to the destruction of the habitat of humans and living beings, on the resources granted by the earth(Figure 1).

Where, a food sovereignty and right will be a utopia towards the global framework of social equality, without mentioning, on the importance of the epistemologies of the new knowledge, they will be omitted to a second or third plane, on the needs of new knowledge, for a society with hungry for learning. Derived from this, an analysis of the various public policies frames the characteristics of protection and strengthening of social food needs, avoiding the disparity and discrepancy on vulnerability of the sociocultural and environmental environments themselves, on the mechanisms food security systems; ranging from insufficient availability and access to ideological questions of global food consumption. Citing important points in which the article refers: "Epistemologies and paradigms of the disciplinary fields of nutrition and food in the training of nutritionists. Analysis and proposals for curricular development"(2012), corresponding 
objects of study must be established in the area of nutrition, not only from the clinical-biological approach, but also from the inclusion of multi-causal approaches, which encompass an approach structural sociological. That is to say, re signifying a social transformation on the ideological conditions, which disadvantage a correct design of public food policies. ${ }^{1-8}$

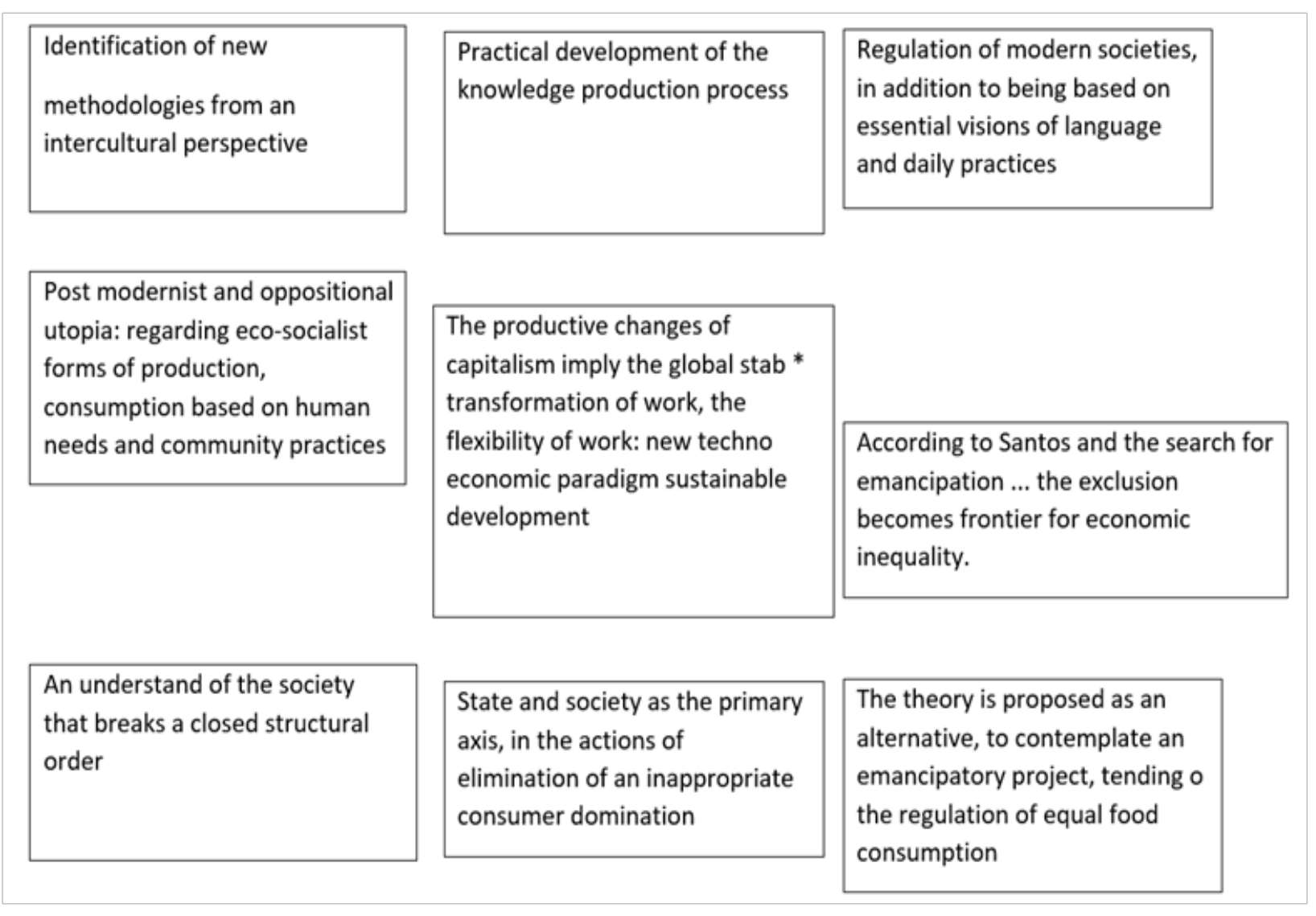

Figure 1 Perspective of the postmodern sociological ideology: Future of the b: enestar alimentary.

\section{Development}

Epistemological reconstruction towards food public policies. The reconstruction of public food policies establishes the significance of the paradigmatic break that consumer ideology currently exercises, atypical of the culturalities of the population, which interfere in the knowledge that contributes to the availability of food that meets biological needs and physiological use. In this sense, proposing a context that marks an epistemological development, will be based on four axes primarily: 1) Strong questions and weak answers, 2) contradiction between urgent measures and civilizational change, 3) loss of nouns, and 4) relationship ghostly between theory and practice.You said approach, it is the transforming generation of a political ideology that establishes systemic parameters that prescribe the contextual protection of food law and sovereignty, in a critical colonizing System that influences the determinants of natural environments and social environments. Where the government intervention must generate a horizontality of the mechanisms of globalizing opening, not established as a means of colonization, rather, as an adaptive and evolutionary mechanism, based on alterity combining the sociocultural elements of the population. Said systems will attend to the necessary considerations to the measures of promotion and prevention of dietary environments, that avoid the contradictions of rational and irrational consumption of food availability. Lacking towards the dignity of human beings, avoiding a discrepancy in the legitimacy of these food policies; as recognized by the Committee on Economic, Social and Cultural Rights (Committee of Desc), as recounted by Oliver de Schuter. The expression congregates a democratized, evolutionary process of human development, referring to three central axes that are: social well-being, economic prosperity and the protection of the conditioning environments towards its environment. Behold, public food policies will be the objectionable instrument that will revalue the centralization of the satisfaction of food needs. Emancipatory rationality. Systemic restructuring based on the epistemological restoration of public policies will contribute to the formation of a worldview not based on a mechanistic paradigm, or rather, a structural phenomenon among the different actors of the social system, in order to restore the development of the environment. As Amartya ${ }^{9}$ states, Thus, in the face of the imminent state of public health alert, these changes will promote incentives for active interaction and consent with the environment, in a harmonious, integrative and axiological way, of the cross-cutting axis of governance and society. Coadjutant to this paradigmatic - epistemological system, you will obtain an adaptability based on the construction of the actions that manage in harmony and integration, of the reasoning of the individuals towards 
the environment, to thereby establish the choice, acquisition and consumption of adequate food available and physical access for their well-being, and full compliance with the statutes of food law.

\section{Discussion}

We live a complex situation that would be very difficult to enter into a disciplinary analysis, which will reduce or totalize and would not generate a series of edges that allow you to see differently which is the social entity on which you could work. Sotolongo says that the important thing is to use the transdisciplinary method without excluding the disciplines but to use them in their dimension, but we must also add other concepts and processes of multidisciplinarity and interdisciplinarity and that this together will generate much richer knowledge. The importance of not getting to colonize knowledge to the communities on the contrary, we can have scientific knowledge, but that does not exclude how it has been done, subjecting, In the following scheme, the creation of new knowledge is contextualized, in accordance with the construction of an ideology that transforms the methodologies of acting in a society. In this, as Boaventura de Souza Santos $^{10}$ refers, in his book epistemologies of the south (2010); the creation of new knowledge through priority knowledge of the needs and particularities of each society, will lead to the creation of correct methodological procedures towards their needs.

Postmodern Sociological Language Perspective: Future of Food Well-being Identification of new methodologies, from an intercultural perspective. Regulation of modern societies, in addition to being based on essential visions of language and daily practices. Practical development of the knowledge production process. Own elaboration: Avila Serrato Salatiel; Society, Epistemology and Methodology. ${ }^{10}$ The productive changes of capitalism imply the global transformation of work, the flexibility of work: New techno-economic paradigm; Sustainable development. Postmodernist and oppositional utopia; regarding eco-socialist forms of production, consumption based on human needs and community practices.

State and society: as the primary axis, in the actions of elimination of an inappropriate consumer domination. An understanding of society that breaks a closed structural order. According to Santos, and the search for emancipation; exclusion becomes a new frontier for economic inequality The theory is presented as an alternative, to contemplate an emancipatory project, tending to the regulation of equal consumption In this sense, making the reference in food production, to generate a improvement in the rise in cost benefit from production to consumption, it is necessary to recreate emancipatory mechanisms that are consistent with a systemic ordering of attention to the needs of the pillars of food sovereignty and food law. This will generate a true rationality of the measurement of food inequalities in social structures; Taking into account some important concepts, recognizing ourselves and seeing ourselves in a neoliberal model, it seems that this is the objective of the state, it is not to understand ourselves from the social point of view but from the economic point of view, if it were in the social sphere, all rights would be fulfilled, the state is the one that is going to promote the neoliberal system and not attending to questions of a social nature. First challenges as you will have with these problems that make us reflect, leave all this to change and organize ourselves in a different way. The identification of methodological strategies from an intercultural perspective, practical development of the production process of knowledge, regulation of modern society as well as being based on essential ideological visions and daily practices. Through the search for mancipation, exclusion becomes a new frontier for economic inequality. Until reaching the utopia presented as a precaution against the possibility that an emancipatory project tends to regulation, producing new equality.

\section{Conclusions}

Understanding the others can only be achieved by generating differentiated methodological mechanisms in the alternative of reaffirming a liberating structure towards the complexity of critical thinking of the corresponding current models and becoming aware of it has impacted it to generate radical changes in its way of thinking, to be and to act accordingly; the commitment is stronger to say if we are doing the right thing, more than to question the other. In this way we will conform the complex perspective of knowledge, a perspective that considers a universe and a subject that knows it from within, changing where causes and effects are not proportional, and exchange and suppose a breakdown of the disciplinary idea in order to access transdiscipline, the self is overcome and the vision of the discipline is eliminated; they are complementary in the way different sabers are linked in which the subjects are agents of social change.

We live in a complex situation that would be very difficult to enter into a disciplinary analysis, which will reduce or totalize and would not generate a series of edges that will allow us to see differently which is the social entity on which it could work; Having said this, the subject who does not have scientific knowledge, nevertheless has social knowledge, has not been allowed to establish dialogical communication with the social scientist. The learning and knowledge complement must have the theoretical foundation for construction, but also the visualization of empiricism. Complexity is the understanding of theories because if not how can we change actors but we are giving both the dissemination and the acquisition of knowledge; the transdisciplinary is going beyond, of a change of vision or mission, etc. In this cross-cutting process, each of the targeting activities, with the aim of social structures, motivate and carry out projects, generate the acquisitions corresponding to these new skills and capacities of food intake, so that they are jointly responsible for transforming their condition of life in a sustainable way.

This will start a paradigmatic vision based on equal opportunities; valuation of the knowledge and knowledge of the inhabitants and their social structures, shared responsibility among families, communities, permanent satisfaction of the needs of the community and the Improvement of human capacities is the engine of individual and collective development.

\section{Acknowledgments}

None.

\section{Conflicts of interest}

Author declare that there is no conflict of interest.

\section{Funding}

None.

\section{References}

1. Andean Veronica. Food Sovereignty and the right to food: choice of public policies from the solidarity economy approach. 
2. Otherness. Education Magazine (online). 2020.

3. Boaventura SS. Epistemologies of the South. Buenos Aires, Argentina CLACSO, 2018.

4. Contreras S, Ramirez M. Decolonize education from Parenting. Electronica Educare Magazine. 2014;18(2):299-303.

5. Licona Gonzalo Hernández. Nutrition and poverty. Evidence-based public policy. Salud Pública de México. 2009;51(Supl 4):S677-S678.

6. Food and Agriculture Organization of the United Nations. The Food system in Mexico. Opportunities of the Mexican countryside in the 2030 Agenda for Sustainable Development. United Nations Organization. Pesa Mexico Methodology: Manual for rural development agents. Mexico City. FAO-Saparpa. 2019.
7. Rivera J, Colchero AM, Fuentes LM, et al. Obesity in Mexico: State of Public Policy and recommendations for its prevention and control National Institute of Public Health. Cuernavaca, Mexico; 2018.

8. Romero Lossaco Jose. Decolonial encounters. Memories of the first school of Our American Decolonial Thought. Venezuelan Institute for Research in Social Sciences and Humanities. 2018.

9. Sen Amartya. Development as freedom. Ecological Gazette. 2020;(55):14-20.

10. Boaventura SS. Decolonize knowledge, Reinvent power. Montevideo, Uruguay: Trilce; 2010. 